\title{
A Study of Linguistic and Cognitive Competence of Primary School Children
}

\author{
Dr. Pranati Satapathy ${ }^{1 *}$
}

\section{ABSTRACT}

The linguistic and cognitive competence of 120 children belonging to three different upper primary school (Oriya medium, English medium and Hindi medium), and equal to 40 each was studied. The results indicated that while the system of schooling was not significantly noticeable in developing cognitive and academic competence. The linguistic competence was found to be significant indicating that in and around the age 10+ and 12+ years the linguistic competence is markedly identified. Whereas the conceptual ability and other related variables like curiosity, learning and piagetian concepts are at par with the system of schooling.

Keywords: Linguistic, Cognitive, Primary School, Children

Schooling is a part of the process of socialization. It is an agent of social change where the objects are selected, arranged, used in order to encourage and foster the process of learning among children both content wise and socially acceptable cultural contents .Schooling is a manmade context of learning situation where knowledge, the basic concepts is prevalent in a given culture are shared among children who attain it. Schooling reflects, projects or mirror the activities, ideas and attitude of a given society or culture. From this point of view schooling assists, fosters and facilitates the cognitive, the affective, the linguistic, the social and the general competence of children (Nanda, 2004). The main objective of the study was to investigate the effect of schooling on children's academic, linguistic and cognitive competence.

\section{METHOD}

\section{Sample}

The present study involved individual testing of 120 children studying in three different coeducational schools in odisha.

40 subjects were chosen from each school i.e, Odia medium, English medium and Hindi medium

\footnotetext{
${ }^{1}$ Assistant Prof. Ravenshaw University, Odisha, India

*Responding Author

(C) 2016 I P Satapathy; licensee IJIP. This is an Open Access Research distributed under the terms of the Creative Commons Attribution License (http://creativecommons.org/licenses/by/2.0), which permits unrestricted use, distribution, and reproduction in any Medium, provided the original work is properly cited.
} 
where as the average age of the children were $10+$ and $12+$ years.

\section{Tools}

The following tests and instruments were administered to all the 120 children.
1. Piagetion measure to measure
: Cognitive competence
2. Psycho-linguistic tasks to measure
: Linguistic competence
3. Vocabulary task to measure
: Linguistic competence
4. Curiosity test to measure
: Cognitive competence
5. Learning tasks to measure
: Cognitive competence
6. The average examination marks of the last qualifying examination.

\section{Procedure}

The subjects were approached personally in their educational institution and after rapport formation; the above tests and instruments together with a personal data sheet seeking information about the subject's age, sex, father's occupation, income etc. were administered to them individually.
Test -1 . Piagetion seriation
(a) Arithmetic
(b) Geometry

\section{Logical reasoning Test (Verbal)}

3. Psycho - Linguistic competence Test (Fluency sub test)

(Vocabulary sub test (comprehension and association )
4. Curiosity Tests
5. Incidental Learning

\section{RESULT AND DISCUSSION}

A total of 25 scores were obtained which assessed children's academic, linguistic and cognitive competencies. The average examination marks of the subjects were also taken as an index of children's academic competence. Thus, A total of 26 scores were available which were subjected to univariate statistical analysis i.e, t-test.

\section{Score - variables used in the study}

A. Average examination marks

B. 1. Piagetion seriation, 2. Arithmetic, 3.Retest, 4.Geometry, 5.Total Logical Reasoning , 6.Modus pones $1^{\text {st }}$ half , 7.Modus Tollen $2^{\text {nd }}$ half , 8.Total

C. Psycho - linguistic ,9. Fluency for letter”ka”, 10. Animal names ,11. Verbal comprehension judge- I, 12. Verbal comprehension judge- II ,

13. Total ,14. No of Association, 15. Use of Synonym,16. Use of Description ,17. Use of Explanation ,18. Use of Demonstration, 19. Use of Errors 
D. Curiosity verbal, 20.odd, 21.Even, 22.Total, 23.Re-test, 24.Non-verbal

E. Learning, 25.Incidental, 26.Free -recall.

Results presented in table -1 shows the means, standard deviations and intergroup $\mathrm{t}$-ratio's with their probability levels of significance.

From the result it was inferred that :

i. The children of the oriya and Hindi medium schools as well as of the English and Hindi medium schools differed significantly in linguistic competence, particularly in fluency for letters.

ii. The children of the oriya and English medium schools as well as of the English and Hindi medium schools differed significantly in linguistic competence, particularly in verbal comprehension

iii. The oriya and English medium schools children differed significantly in linguistic competence as rated by judge -II.

iv. In linguistic competence (No of associations ), all three groups of school children differed significantly from each other.

v. The children of the oriya and English medium schools as well as of the English and Hindi medium schools differed significantly in use of synonyms.

vi. The children of the oriya and Hindi medium schools as well as of the English and Hindi medium schools differed significantly in use of description.

vii. The children of the oriya and Hindi medium schools as well as of the English and Hindi medium schools differed significantly in use of explanations.

viii. The children of the oriya and Hindi medium schools as well as of the English and Hindi medium schools differed significantly in error committed in linguistic competence.

From the above result, it was found that the children of the three different schools ( Oriya , English and Hindi medium) differed significantly from each other only in one aspect i.e, linguistic competence. No other significant difference was noticed in any other variable measuring other competencies. 
Table I, Means, SD And Inter Group “ $t$ ” Ratio Of 26 Scores Of Oriya, English And Hindi Medium Schools $(\mathrm{N}=40 \mathrm{X3}=120)$

\begin{tabular}{|c|c|c|c|c|c|c|c|c|c|}
\hline \multirow{2}{*}{$\begin{array}{l}\text { S Var. } \\
\text { N. }\end{array}$} & \multicolumn{2}{|c|}{ SCHOOL 1} & \multicolumn{2}{|c|}{ SCHOOL 2} & \multicolumn{2}{|c|}{ SCHOOL 3} & \multirow{2}{*}{$\begin{array}{c}\text { SCHOOL } \\
(1-2) \\
t\end{array}$} & \multirow{2}{*}{$\begin{array}{c}\text { SCHOOL } \\
\begin{array}{c}(1-3) \\
t\end{array}\end{array}$} & \multirow{2}{*}{$\begin{array}{c}\text { SCHOOL } \\
\begin{array}{c}(2-3) \\
t\end{array}\end{array}$} \\
\hline & Mean & SD & Mean & SD & Mean & $\mathrm{SD}$ & & & \\
\hline 1 & 57.30 & 16.40 & 41.20 & 26.71 & 39.98 & 7.18 & 1.3044 & 2.0073 & .6415 \\
\hline 2 & 2.10 & 1.10 & 2.64 & 1.11 & 2.63 & .95 & .9064 & .9034 & .0156 \\
\hline 3 & 2.30 & 1.13 & 2.61 & 1.38 & 2.83 & 1.05 & .4975 & .8406 & .3263 \\
\hline 4 & 3.50 & 1.86 & 3.02 & 1.21 & 2.26 & .84 & .5860 & 1.6731 & 1.1756 \\
\hline 5 & 5.60 & 2.40 & 5.65 & 1.79 & 4.87 & 1.57 & .0369 & .5763 & .6228 \\
\hline 6 & 3.30 & 1.11 & 3.60 & 1.39 & 3.38 & 1.37 & .3609 & .0993 & .2593 \\
\hline 7 & 2.30 & 1.99 & 3.38 & 1.76 & 3.35 & 1.51 & 1.3913 & 1.3816 & .0355 \\
\hline 8 & 5.60 & 2.44 & 6.98 & 2.13 & 6.75 & 2.51 & .9087 & .7631 & .1403 \\
\hline 9 & 9.25 & 3.70 & 17.65 & 7.44 & 16.13 & 6.56 & $2.4344 * *$ & $2.1458^{*}$ & .3674 \\
\hline 10 & 15.43 & 6.16 & 17.53 & 8.52 & 16.18 & 3.82 & .5133 & .1996 & .3297 \\
\hline 11 & 5.52 & 3.37 & 10.13 & 6.67 & 4.64 & 1.27 & $2.1025 *$ & .6839 & $2.6395 * *$ \\
\hline 12 & 5.92 & 3.08 & 10.01 & 6.59 & 4.79 & 1.24 & 1.8681 & .8512 & $2.5227^{*}$ \\
\hline 13 & 5.70 & 3.12 & 10.07 & 6.62 & 5.81 & 2.30 & 2.0004 & .0608 & 1.7541 \\
\hline 14 & 22.80 & 21.32 & 178.08 & 82.39 & 58.93 & 28.01 & $4.8921^{* *}$ & $3.1287 * *$ & $3.6066 * *$ \\
\hline 15 & 3.10 & 2.21 & 4.18 & 3.04 & 1.63 & 1.62 & 1.0572 & $2.0736^{*}$ & $2.8217^{*}$ \\
\hline 16 & 1.98 & 1.97 & 4.15 & 1.92 & 3.53 & 1.52 & $2.5329 * *$ & 2.0406 & $.6500 *$ \\
\hline 17 & 1.78 & 1.56 & 3.60 & 1.39 & 3.80 & 1.68 & 2.5180 & $2.6463 * *$ & .2206 \\
\hline 18 & 2.93 & 2.45 & 2.73 & 1.51 & 3.53 & 1.70 & .2547 & .4889 & .7907 \\
\hline 19 & 10.25 & 5.45 & 5.33 & 5.31 & 6.70 & 2.07 & $2.2286^{*}$ & 1.6401 & .8326 \\
\hline 20 & 6.10 & 1.30 & 5.58 & 1.52 & 5.30 & 1.98 & .3822 & .5939 & .2165 \\
\hline 21 & 5.25 & 1.77 & 4.30 & 1.45 & 4.90 & 1.93 & .8295 & .2864 & .5397 \\
\hline 22 & 11.35 & 2.44 & 9.87 & 2.17 & 10.25 & 2.79 & .6006 & .4368 & .1619 \\
\hline 23 & 10.25 & 5.41 & 10.40 & 2.17 & 11.75 & 3.03 & .0596 & .5593 & .5231 \\
\hline 24 & 7.58 & 3.14 & 7.95 & 2.75 & 7.78 & 3.10 & .1970 & .1067 & .0896 \\
\hline 25 & 17.35 & 6.29 & 10.52 & 5.95 & 12.18 & 7.32 & 1.5519 & 1.3893 & .4176 \\
\hline 26 & 5.13 & 1.84 & 5.53 & 2.24 & 6.25 & 1.60 & .3098 & .8293 & .5124 \\
\hline
\end{tabular}

The combined efforts of psychology and Linguistic are an attempt to understand the language better and to know the development of linguistic competence of the child. Linguistic ability is a complex process ranging from the acquisition of simple automatic skills to an understanding of abstract conceptual and aesthetic meanings, all occurring in the same situation. Fluency is otherwise "language in use "meaning speaking at normal conversational speed i.e, 500 sounds per minute under a speech set. The core vocabulary of the first language is learned at home in the greatest struggle of the child to communicate his needs. He / she learns vocabulary from his /her 
environment and culture, from the person with whom he/she lives, from things he/she needs, from action he/she wants to perform. Each individual knows a limited vocabulary which is facilitated by the schooling (Clark and Clark,1977; Greenfield and Smith , 1976 ; and Gibson 1969 ).

In this study, it was noticed that the children of the Hindi and Oriya medium school as well as of the Hindi and English medium school differed significantly from each other in fluency for letters. Results clearly indicate that the mean score of the Hindi medium school children was much lower than that of the English and Oriya medium school children. It was also observed that the children of the English medium school were more fluent in expression than oriya and Hindi medium school children. Similar results were also obtained in case of verbal comprehension, No. of Associations, use of synonym and description. The Oriya medium school children scored significantly higher than the English as well as Hindi medium school children in use of explanation and also errors. Thus, in a quality scale (five categories) i.e, synonym, use and description, explanation, demonstration and error, the English medium children were better in former three while the Oriya medium school children were doing well in latter two.

The main aim of the present investigation was to investigate whether there was any differential schooling effect on children's competence? The findings suggested that there was no significant difference with regard to cognitive and academic competence among children studying in different medium of (instruction) schools (schooling effect was not significant) but schooling effect was noticeable and significant on linguistic competence. Furthermore, around the age of $10+$ and /or 12+years of children, there is no difference in conceptual ability but there exists a difference in linguistic ability.

\section{REFERENCES}

Clark,H.H and Clark , E.V.(1977) . "Psychology and Language : An Introduction to psycho linguistic”, New York : Harcourt Brace Jovanovich.

Gibson,E.J (1969) .’Principles of perceptual learning and development”. NewYork: Appleton Century crofts.

Greenfiled ,P.M and J.A (1976) . "The structure of communication in early language development”. New York: Academic press.

Nanda,G.K (2004) “ Effect of medium , system of schooling, sex ,grade and popularity of children “. Unpublished Doctoral Dissertation, Utkal University. 